\title{
As-cast microstructures and behavior at high temperature of chromium-rich cobalt-based alloys containing hafnium carbides
}

\author{
Patrice Berthod and Elodie Conrath \\ Institut Jean Lamour \\ Department $N^{\circ} 2$ : Chemistry and Physic of Solids and Surfaces \\ Team "Surface and interface, chemical reactivity of materials" \\ Faculty of Sciences and Techniques, Nancy - University, \\ B.P. 70239, 54506 Vandoeuvre-lès-Nancy - France
}

Corresponding author's e-mail : pberthodcentralelille1987@orange.fr

Corresponding author's phone: (33)3 83684666 and fax number: (33)3 83684611

\section{Postprint version of the article}

Materials Chemistry and Physics 143 (2014) 1139-1148

http://dx.doi.org/10.1016/j.matchemphys.2013.11.014

\begin{abstract}
Hafnium is often used to improve the high temperature oxidation resistance of superalloys but not to form carbides for strengthen them against creep. In this work hafnium was added in cobalt-based alloys for verifying that HfC can be obtained in cobalt-based alloys and for characterizing their behavior at a very temperature. Three Co-25Cr-0.25 and 0.50C alloys containing 3.7 and 7.4 Hf to promote HfC carbides, and four $\mathrm{Co}-25 \mathrm{Cr}-0$ to $1 \mathrm{C}$ alloys for comparison (all contents in wt.\%), were cast and exposed at $1200^{\circ} \mathrm{C}$ for 50 hours in synthetic air. The HfC carbides formed instead chromium carbides during solidification, in eutectic with matrix and as dispersed compact particles. During the stage at $1200^{\circ} \mathrm{C}$ the $\mathrm{HfC}$ carbides did not significantly evolve, even near the oxidation front despite oxidation early become very fast and generalized. At the same time the chromium carbides present in the $\mathrm{Co}-\mathrm{Cr}-\mathrm{C}$ alloys totally disappeared in the same conditions. Such HfC-alloys potentially bring efficient and sustainable mechanical strengthening at high temperature, but their hot oxidation resistance must be significantly improved.
\end{abstract}

Keywords: alloys (A); solidification (B); electron microscopy (C); hardness (D); microstructure (D); phase transition (D); oxidation (D) 


\section{Introduction}

Many superalloys for application at very high temperature are obtained by solidification from a liquid melt. Differently to the ones obtained by forging after casting or by powder metallurgy, the solidified superalloys generally present big grains if the cooling and solidification rates are not too high [1]. Such coarse microstructures are generally favorable to high level of mechanical properties at high temperatures. It is usually considered that the best cast superalloys in this field are the single-crystal $\gamma^{\prime}-$ reinforced nickel-based superalloys [2], and also some of the directionally solidified cobalt-based superalloys for example. Their levels of performance are as high as of the ones of the best Oxide Dispersion Strengthened alloys. But some pieces' geometries, e.g. more compact than elongated, cannot be easily realized using directionally or single-crystal solidification. In such cases equi-axed polycrystalline superalloys must be used. The metallurgy of such alloys implies the use of particles which efficiently reinforce the grain boundaries, the weakest zones in these alloys for working temperatures higher than $800^{\circ} \mathrm{C}$ typically. When the working temperature is especially high on long times, e.g. $1200^{\circ} \mathrm{C}$, the particles reinforcing grain boundaries must be particularly refractory and stable at this temperature on times long enough.

The equi-axed cobalt-based superalloys represent an important family of cast superalloys strengthened by carbides [3]. In many cases these carbides are chromium carbides, the most often of the eutectic $\mathrm{Cr}_{7} \mathrm{C}_{3}$ or $\mathrm{Cr}_{23} \mathrm{C}_{6}$ types, but such carbides are not very stable at high temperatures. The tantalum carbides are also often used and are better than the former carbides in term of stability at high temperature, but they tend to evolve in terms of morphology and of volume fractions [4,5]. Fortunately there are other very stable carbides, of the MC-stoichiometry too, which may show a better thermal stability and then a better mechanical sustainability: the hafnium carbide HfC $[6,7]$.

The addition of hafnium is generally done by targeting more or less $1 \mathrm{wt} . \%$ (e.g. from 0.25 to $1.5 \mathrm{wt} . \%$ ) in order to slower the oxidation rate at high temperature for commercial alloys [8,9], iron-based $(\mathrm{Cr}, \mathrm{Al})$ - rich bulk alloys [10,11], aluminides $[12,13]$ and bond coats supporting thermal barrier coatings $[14,15]$, to cite only some of the most recent works. In contrast high quantities of Hf are much more rarely 
introduced in refractory bulk alloys to promote the development of an interdendritic network of HfC reinforcing carbides.

In this work this is this use of hafnium, as carbide-forming element, which is of interest, and three alloys belonging to the Co-Cr-C-Hf system were considered. Their targeted chemical compositions were selected in order to allow them to be oxidationresistant at high temperature (high amount in chromium), to contain carbides in significant volume fractions (two carbon contents high enough), and to obtain two types of carbides populations:

either one nature: HfC achieved by taking atomic contents of $\mathrm{C}$ and of $\mathrm{Hf}$ equals to one another,

- $\quad$ or two different natures: a part of HfC carbides and a part of chromium carbides by choosing an atomic content of hafnium lower than the carbon one).

Thus, by choosing different values of carbon content and of hafnium content between two levels for each of them, the alloys of this study are microstructurally more diversified as previously studied [6]. This allows a wider exploration of the high temperature capabilities of alloys belonging to this quaternary system.

The high temperature properties which were under study in this work are the metallurgical stability of alloys, which is of great importance for the potential of mechanical resistance, and at a smaller scale, the resistance to high temperature oxidation. The temperature considered was taken equal to $1200^{\circ} \mathrm{C}$, as is to say the maximal one which can be reasonably considered for equi-axed cast cobalt-based superalloys.

\section{Material and methods}

\subsection{The studied alloys}

Three alloys based on cobalt and containing chromium (targeted content: 25 wt.\% Cr), carbon (targeted contents: 0.25 and $0.50 \mathrm{wt} . \% \mathrm{C}$ ) and hafnium (3.72 and 7.44 wt.\% Hf) were elaborated by foundry in a High Frequency induction furnace (CELES). This was done in an inert atmosphere of pure argon (300 millibars at ambient temperature) after three \{vacuum, Ar introduction $\}$-cycles performed using a Pfeiffer Vacuum DUO 20M primary pump and a Pfeiffer Vacuum Single Gauge device for the 
pressure measurement/control. During heating, melting, dwell in liquid state, solidification and cooling, the metallic charges or synthesized alloys were constantly isolated from the laboratory air with a silica tube. The pure elements (Alfa Aesar, more than 99.9 wt.\% of purity) were placed in the segmented water-cooled copper crucible of the furnace, by mixing them together. The operating parameters of fusion were:

$$
\text { - frequency } \approx 110 \mathrm{kHz}
$$$$
\text { - voltage } \approx 4000 \mathrm{~V} \text {, }
$$

- holding time in the liquid state $\approx$ about 3 minutes (to be sure that melting was total and the melt chemically homogenized before solidification).

The cooling was realized by decreasing the power and the melt solidified in the same copper crucible (total solidification time $\approx 20-25$ seconds). The temperature decreased down to less than $500^{\circ} \mathrm{C}$ during less than one minute.

Four other alloys - a binary one Co - 25 wt.\% Cr and three ternary ones Co - 25 wt.\% $-0.25,0.50$ and 1 wt.\% C - were additionally elaborated following the same procedure.

\subsection{Preparation of the samples}

After complete cooling to room temperature the compact ingots (about $40 \mathrm{~g}$ ) were cut using a BUEHLER Delta Abrasimet Cutter, then an automated cutting unit: a BUEHLER Isomet linear precision saw.

The parts destined to the microstructure characterization in the as-cast condition were embedded in a plastic mold in which was thereafter poured a cold mixture composed of Araldite Resin DBF (82\% in mass) and hardener HY956 (18\% in mass), both from ESCIL. The mounted samples were polished using a BUEHLER Phoenix Alpha Grinding/Polisher unit. This was done first with SiC papers with grades from 120 or 240 up to 1200 (cooling lubricant: water), and second with a textile disk enriched with diamond particles spray (ESCIL) (cooling: DP-Lubricant Red from Struers). With the obtained mirror-like surface state these samples were ready for metallographic examination of the alloys' microstructures.

Other parts, destined to the oxidation tests in thermo-balance, were cut with the same apparatus but by respecting specific dimension conditions (parallelepipeds of 
about $8 \times 8 \times 3 \mathrm{~mm}^{3}$ ). They were polished by using 240 -grit SiC papers to smooth edges and corners (cooling lubricant: water), then all around polished with 1200-grit $\mathrm{SiC}$ papers, especially the two main planar faces and the four planar sides.

\subsection{Metallographic characterization and indentation of the seven as-cast alloys}

The Hf-containing alloys and the Hf-free ones were observed using a Scanning Electrons Microscope (SEM, model: JSM 6010 LA from JEOL) under an acceleration voltage of $20 \mathrm{kV}$, essentially in the Back Scattered Electrons mode (BSE). The global chemical composition of each alloy was determined using the Energy Dispersive Spectrometry device equipping the SEM. Pinpoint EDS measurements were additionally performed in three locations in the matrix as well as in the coarsest particles of the other phases. X-Ray maps were also performed to study the distribution of the four elements $(\mathrm{Co}, \mathrm{Cr}, \mathrm{C}, \mathrm{Hf})$ in the microstructure. They allowed clearly identifying particles when too small or elongated to be efficiently analyzed by pinpoint EDS.

Micrographs were taken a different magnifications $(\times 250,500$ or 1000$)$ and in each case three out of the $\{\times 1000\}$-pictures were analyzed using the Photoshop CS software of Adobe, for specifying the average surface fractions and the corresponding standard deviations of the present phases.

A Testwell Wolpert indenter was used, three times by as-cast alloy, to bring an average value and a standard deviation one for the Vickers hardness of all alloys.

\subsection{High temperature exposures and metallographic / hardness characterization}

The three Hf-containing alloys, and two of the Hf-free ones (the ternary alloys with the same carbon contents as the Hf-containing ones, i.e. 0.25 and $0.50 \mathrm{wt} . \% \mathrm{C}$ ), were exposed to $1200^{\circ} \mathrm{C}$ during 50 hours in a furnace through which a flow of synthetic air $\left(80 \% \mathrm{~N}_{2}-20 \% \mathrm{O}_{2}\right)$ passed. The heating rate was $+20 \mathrm{~K} \cdot \mathrm{min}^{-1}$ and the cooling rate was -5 K.min ${ }^{-1}$.

The oxidized samples were thereafter coated with a fine gold layer using a JEOL JFC-1200 Fine Coater, to give electric conductivity to the external side of the oxide scales. This allowed thereafter realizing the electrolytic deposition, on the oxidized samples (cathodically polarized), of metallic nickel resulting of the reduction of the $\mathrm{Ni}^{2+}$ cations present in the Watt's bath. This one was heated at $50^{\circ} \mathrm{C}$ (bain-marie: Julabo 13 , heater: Julabo ED), and renewed by the electrolytic oxidation of nickel anodes using a 
Multimetrix XAI525 delivering a current of about 0.04 A (to achieve a current density of about $\left.1.5 \mathrm{~A} / \mathrm{dm}^{2}\right)$.

With such mechanical protection of the surrounding oxide scales the oxidized samples were cut with the same cutting machines described above, with minimization of the risk of deterioration of the scales. After metallographic preparation (embedding and polishing), the oxidized samples were observed in cross-section.

The bulk microstructures were finally characterized by metallography and indentation, following the same procedures as already described above for the as-cast samples (SEM/EDS measurements, SEM/BSE observations, image analysis of micrographs for the surface fractions of the different phases, indentation...). The oxide scales and the subsurface microstructures were also observed by SEM/BSE and analyzed by SEM/EDS.

\section{Results}

\subsection{Chemical compositions and as-cast microstructures of the alloys}

The general chemical compositions of the seven alloys just after their elaboration are given in Table 1 . The chromium and hafnium contents are globally well respected, even if the EDS are a little higher than targeted.

The as-cast microstructures of the alloys are illustrated by selected micrographs presented in Fig. 1 for the four Hf-free binary and ternary alloys. The binary alloy seems to be single-phased while the three ternary alloys contain chromium carbides. This is not obvious for the Co-25Cr- $0.25 \mathrm{C}$ alloy: its carbides are very rare and small (if they really exist). In contrast the $\mathrm{Co}-25 \mathrm{Cr}-0.50 \mathrm{C}$ alloy presents visible interdendritic chromium carbides (darker than matrix). In the Co-25Cr-1C alloy the chromium carbides are present as an interdendritic network which is almost continuous.

X-ray diffraction was performed on these four alloys (Fig. 2) but the results did not permit identifying the carbides' nature. This is probably due to the too low volume fractions of these carbides, even in the C-richest alloy. In contrast the XRD spectra showed that the matrix is composed of two parts: a hexagonal matrix (HCP) and an austenitic matrix (FCC). This is maybe different for the C-richest alloy which seems having kept the FCC crystalline network. The high temperature FCC matrix has obviously no time enough to transform during the rapid cooling, notably in the case of the $\mathrm{Co}-25 \mathrm{Cr}-1 \mathrm{C}$ alloy. This can be explained by the fact that its matrix is the less rich in 
chromium (about 22wt.\%, Table 2) because of its greatest fraction of chromium carbides: since it is known that chromium tends to increase the temperature of the $\mathrm{FCC} \rightarrow \mathrm{HCP}$ transformation, a lower $\mathrm{Cr}$ content may have delayed the FCC/HCP transformation to temperatures too low for allowing its realization.

The microstructures of the as-cast Hf-containing alloys are illustrated in Fig. 3. The Co-25Cr-0.25C-3.72Hf alloy is composed of a dendritic matrix and of white interdendritic particles. These particles are either of a pre-eutectic type (compact/polygonal) for some of them, or of a eutectic-like type (for many of them). Such white particles are also present, with the two shapes, in the two other Hfcontaining alloys. The two types of particles are much more present in the Hf-richest Co-25Cr-0.50C-7.44Hf alloy. EDS pinpoint measurements showed that they are rich in hafnium and carbon, which let think that these particles are HfC carbides. This was confirmed by XRD runs (examples in Fig. 4) and X-ray maps (example in Fig. 5). However another type of carbide also exists - chromium carbides - but only in the Co25Cr-0.50C-3.72Hf alloy. The Hf content of this alloy is obviously too low for its high $\mathrm{C}$ content $(0.50 \mathrm{wt} . \%)$ to allow involving all the carbon atoms in the $\mathrm{HfC}$ carbides formation. All the hafnium atoms have themselves been involved in the formation of carbides since the residual hafnium content in matrix is extremely low (Table 2). Furthermore, by considering the standard deviation values in the Table 2, which are of the same order as the average values, one can think that there is no hafnium in the matrix. The values not equal to zero were probably due to the proximity of subjacent HfC carbides.

For each as-cast alloy three $\{\times 1000\}$-micrographs were taken with the SEM in the BSE mode to be analyzed with Photoshop in order to specify the average carbide surface fraction and the corresponding standard deviation value. The results are graphically given in Fig. 6. The fraction of chromium carbides in the ternary alloys logically increases with the carbon content. In contrast, it is much more the hafnium content than the carbon content that imposes the values of the carbide fractions in the Hf-containing alloys: the population of HfC carbides is doubled when the Hf content is doubled, and with only $0.5 \mathrm{wt} . \% \mathrm{C}$ the surface fraction of $\mathrm{HfC}$ reaches the same level as the chromium carbides surface fraction for $\mathrm{x}=1 \mathrm{wt} . \% \mathrm{C}$ in the ternary $\mathrm{Co}-25 \mathrm{Cr}-\mathrm{xC}$ system. However, doubling the carbon content has almost no effect except the 
appearance of a small quantity of additional chromium carbides in the Co- $25 \mathrm{Cr}-0.50 \mathrm{C}$ 3.72Hf alloy.

\subsection{Bulk microstructures and hardness of the alloys after $50 \mathrm{~h}$ at $1200^{\circ} \mathrm{C}$}

The three Hf-containing alloys and the two ternary alloys with the same carbon contents (Co-25Cr-0.25C and $\mathrm{Co}-25 \mathrm{Cr}-0.50 \mathrm{C})$ were exposed to $1200^{\circ} \mathrm{C}$ during 50 hours, in order to test the metallurgical stability of the Hf-containing alloys by comparison to the Hf-free alloys. Additional information was also expected about the oxidation resistance of the alloys by having chosen to perform these high temperature exposures in an oxidizing atmosphere (synthetic air).

The examination of the bulk microstructure of the five alloys allowed seeing different types of microstructure modifications. They are illustrated by micrographs taken on the heated alloys which can be compared to the micrographs showing the initial microstructure: in Fig. 7 for the two ternary alloys, in Fig. 8 for the $\{0.25 w t . \%$; Hf $\}$-containing alloy and in Fig. 9 for the two $\{0.50 \mathrm{wt} . \% \mathrm{C}$; Hf $\}$-containing alloys. The exposure at $1200^{\circ} \mathrm{C}$ for 50 hours has led to the total disappearance of the chromium carbides in the two ternary alloys. The chromium carbides which were initially present in the Co-25Cr-0.50C-3.72Hf alloy, have also disappeared. In contrast, the HfC carbides have shown a better high temperature stability. Indeed the surface fractions of HfC seem to have qualitatively not changed significantly, and the two shapes, preeutectic and eutectic, are still present. One can just notice that the eutectic HfC carbides seem to be a little fragmented by comparison with the initial microstructure.

The surface fraction of HfC carbides were quantitatively specified by image analysis using Photoshop. The results (average \pm standard deviation) are plotted in Fig. 10. The HfC surface fractions seem to have decreased a little in the two $\{3.72 \mathrm{wt} . \% \mathrm{Hf}\}$ containing alloys. This is especially true for the $\{0.25 \mathrm{wt} . \% \mathrm{C}-3.72 \mathrm{wt} . \% \mathrm{Hf}\}$-containing alloy, but less for the $\{0.50 \mathrm{wt} . \% \mathrm{C}-3.72 \mathrm{wt} . \% \mathrm{Hf}\}$-containing alloy. Indeed, for the latter alloy, the disappearance of the chromium carbides has released carbon atoms which were thereafter involved in the precipitation of few supplementary hafnium carbides. The appearance of these additional HfC carbides limited the decrease in HfC carbide fraction in this alloy. The decrease in HfC carbide fraction is a little more sensible for 
the Hf-richest alloy, in which the HfC surface fraction has lost about 3 surf.\%. There is no difference between the general chemical composition of the five alloys after 50 hours at $1200^{\circ} \mathrm{C}$ and their initial bulk composition in their as-cast condition (Table 3), as verified by SEM/EDS measurements. Concerning the chemical composition of the matrix of the ternary alloys and of the Hf-containing alloys (Table 4), the chromium contents are not changed between the two states (as-cast and aged $50 \mathrm{~h}$ at $1200^{\circ} \mathrm{C}$ ). However one can notice that it is more obvious that Hf is totally absent in the matrix of the aged Hf-containing alloys.

The room temperature Vickers hardness under a load of $30 \mathrm{~kg}$ is plotted in Fig. 11 versus the carbon content for the two metallurgical states, as-cast (seven points) and aged during 50 hours at $1200^{\circ} \mathrm{C}$ (five points). Concerning the as-cast binary and ternary alloys, the hardness logically increases with the carbon content, from about 245 to about $405 \mathrm{Hv}_{30 \mathrm{~kg}}$. One can also notice first that the hardness of the as-cast $\mathrm{Co}-25 \mathrm{Cr}-1 \mathrm{C}$ is close to the one of the as-cast $\mathrm{Co}-25 \mathrm{Cr}-0.50 \mathrm{C}-7.44 \mathrm{Hf}$ alloy which presents the same surface fraction of carbides. Second, the two other as-cast Hf-containing alloys are harder than the as-cast ternary alloys with $0.25 \mathrm{wt} . \% \mathrm{C}$ and $0.50 \mathrm{wt} . \% \mathrm{C}$, what is a logical consequence of their higher carbide fractions seen above. After exposure at $1200^{\circ} \mathrm{C}$ the hardness of the $\mathrm{Co}-25 \mathrm{Cr}-0.25 \mathrm{C}$ and $\mathrm{Co}-25 \mathrm{Cr}-0.50 \mathrm{C}$ alloys are significantly lowered, down to about 230 (to compare to about 265 initially) for the first alloy and down to about 240 (to compare to about 290 initially) for the second alloy. The new hardnesses of these two aged alloys are of the same level as for the as-cast binary alloy. This is not surprising since carbides have obviously completely disappeared from the microstructures of these alloys. For the Hf-containing alloys too, one can notice a hardness decrease due to the high temperature exposure. The hardness loss is rather limited for the Hf-richest alloy although it was seen above that its carbide surface fraction had seemingly more decreased during the high temperature exposure than for the two other Hf-containing alloys. Curiously this is for these two latter alloys that the hardness losses were the most significant, notably for the $\{0.50 \mathrm{wt} . \% \mathrm{C} ; 3.72 \mathrm{wt} . \% \mathrm{Hf}\}$ containing alloy. This is maybe due to the total disappearance of its (rather rare) chromium carbides. 


\subsection{Surface states of the alloys after exposure during $50 \mathrm{~h}$ at $1200^{\circ} \mathrm{C}$}

The five alloys exposed at high temperature underwent oxidation. Their surface and sub-surface states are illustrated by selected SEM/BSE micrographs, in Fig. 12 for the two $\{0.25$ wt. $\%\}$-containing alloys, and in Fig.13 for the three $\{0.50$ wt. $\%\}$ containing alloys. At the end of the 50h-stage the two ternary alloys obviously showed a double oxidation regime. Indeed, some surface parts were still oxidizing rather slowly with an oxide-alloy interface still planar. But the local chromium content became very low on the extreme surface of the alloys (11-12 wt.\% Cr instead 25 wt.\% initially), which means that the loss of the local chromia-forming behavior was imminent. At the same time other parts of the same samples had obviously already started catastrophic oxidation: deep penetration of corrosion with very thick and multi-constituted oxide scales $\left(\mathrm{CoO}, \mathrm{CoCr}_{2} \mathrm{O}_{4}\right.$ and sometimes $\left.\mathrm{Cr}_{2} \mathrm{O}_{3}\right)$, and chromium contents on extreme surface paradoxically higher (about $18 \mathrm{wt} . \%$ ) but resulting of the kinetic competition between oxide/alloy interface recession and $\mathrm{Cr}$ diffusion from the alloy.

The Hf-containing alloys maybe behaved as chromia-forming in the first stages but, after the $50 \mathrm{~h}$-stage at $1200^{\circ} \mathrm{C}$, they all present a thick complex oxide scale composed of $\mathrm{CoCr}_{2} \mathrm{O}_{4}$ and $\mathrm{Cr}_{2} \mathrm{O}_{3}$, with here and there small hafnium oxides $\mathrm{HfO}_{2}$. In contrast, contrarily to the ternary alloys, the carbides' networks of these Hf-containing alloys are still present, from bulk to the extreme surface.

\section{Discussion}

In this study it was found again that, in chromium-rich cobalt-based alloys, the HfC carbides crystallize instead chromium carbide during solidification, as this was earlier observed in previous works $[6,7]$ and here first detected by XRD. Such priority was already observed for other MC carbides as tantalum carbides for example $[5,16]$. In fact, two types of particles appearing white in BSE mode (high average atomic number) were observed: script-like particles forming an interdendritic compound with matrix, and some dispersed coarse polygonal particles. Both were clearly identified by EDS pinpoint measurements as being $\mathrm{HfC}$ carbides. If the script-like $\mathrm{HfC}$ carbides undoubtedly are eutectic carbides appeared at the end of solidification, one can guess that the compact polygonal carbides may have appeared at the earliest stage of solidification. Such pre-eutectic crystallization of TaC carbides was recently observed 
by metallography, and interpreted by thermodynamic calculations, for a $\mathrm{Cr}$-rich Cobased alloy containing very high amounts in C (1wt.\%) and Ta (15 wt.\%) [17]. This is the reason why the first type of HfC carbides was called eutectic carbide above while the second type was called pre-eutectic carbide. If the eutectic HfC carbides can be considered as favorable to good mechanical properties at high temperature, the preeutectic carbides have probably not such beneficial effect. Inversely, due to their low presence in the microstructure, such carbides are not detrimental for the machinability and room temperature impact toughness of the alloys.

It was previously observed in another alloy that the HfC carbides are especially stable at high temperature [6], better than TaC carbides in a similar alloy base. This was found again with these three alloys with varied $\mathrm{C}$ and $\mathrm{Hf}$ contents. Here too no hafnium was detected in matrix, this showing that the Hf atoms captured all the carbon atoms to form a maximum of $\mathrm{HfC}$ carbides during solidification. Further, even after 50 hours at a so high temperature as $1200^{\circ} \mathrm{C}$, only the morphology of the eutectic carbides was a little changed. The HfC carbides were however less fragmented than TaC carbides in cobaltbased alloys as earlier observed for the same stage temperature and duration. Indeed it seems that no significant part of HfC carbides was lost (despite some present results of image analysis) since no hafnium was detected in matrix after the high temperature exposure. The room temperature hardness was consequently kept rather high, and the mechanical properties at high temperature may be also probably maintained at a high level.

This is totally different to what was here observed for the ternary alloys which lost all their chromium carbides. As earlier encountered for some \{chromium carbides containing simple cobalt alloys [18] the fast oxidation can be considered as responsible of this phenomenon: general oxidation of the alloy including the part of carbon initially remained in solid solution in the matrix, destabilization of the chromium carbides and then progressive dissolution of these ones with delivering of their constitutive $\mathrm{Cr}$ and $\mathrm{C}$ atoms. As revealed by the $\mathrm{Cr}$ contents being still at around $25 \mathrm{wt} \%$ in matrix, the $\mathrm{C}$ atoms diffused thereafter towards the oxidation front to be themselves oxidized, this acting until the total disappearance of the chromium carbides.

The presence of some $\mathrm{Hf}$ atoms or $\mathrm{C}$ atoms in the neighbor matrix is obviously not necessary for the stability of the $\mathrm{HfC}$ carbides. Indeed, despite the fast oxidation acting 
also on surface of the Hf-containing alloys, the HfC carbides are, at the end of the high temperature stage, still present in the bulk as well as very close to the oxide/alloy interface. There too, rather than dissociating into $\mathrm{C}$ and $\mathrm{Hf}$ atoms, the $\mathrm{HfC}$ carbides are transformed into $\mathrm{HfO}_{2}$ oxides which are thereafter encompassed in the complex oxide scale growing inwards the alloy.

Concerning the first mechanical characterization of these alloys, only done at room temperature in the present work, one can remark that the hardness of the alloys is rather high (because of the especially high hardness of $\mathrm{HfC}$ (around $3000 \mathrm{Hv}$ [19]) but it remains still compatible with reasonable machinability) and one can guess that the creep resistance is superior to many of the other carbides-reinforced cast cobalt-based alloys.

But, for the moment the main problem clearly remains the behavior in oxidation at high temperature. Indeed it must be seriously improved for allowing uses in oxidizing gaseous conditions. This may be done by enriching the alloys' bulk in chromium (up to 30 wt.\% and even more). But such increase in $\mathrm{Cr}$ content may induce decrease for the solidus temperature of the alloys, and consecutively this may lead to a lowering of their creep resistance. Maintaining the chromium content at the value of $25 \mathrm{wt} . \%$, which can be considered as a minimal limit for having some chances to keep a chromia-forming behavior for cobalt-based alloys, was here precisely chosen to favor creep resistance. However other way can be also the deposit of protective coating, for example by chromium pack-cementation process to enrich in this element only the surface and subsurface. Such operation has probably all chances to be successful thanks to first the very high stability of HfC carbides when in competition with chromium carbide formation, and second to the probable total absence of carbon atoms in matrix [20].

\section{Conclusions}

The HfC carbides successfully obtained in these alloys, thanks to Hf contents especially high by comparison to usually chosen for only improvement of oxidation behavior, have probably high potential mechanical properties, with a better sustainability than for the other MC-type tantalum carbides. This progress in high temperature mechanical properties needs now to be evaluated. However, in order to allow this mechanical characterization for example at $1200^{\circ} \mathrm{C}$, the high temperature 
oxidation behavior of these alloys must be significantly improved. Several solutions exist for that, and further works will be undertaken in this way.

\section{Acknowledgements}

The authors wish to thank very much Pascal Villeger who performed the X-Ray diffraction runs.

\section{References}

[1] C. T. Sims, W. C. Hagel, The Superalloys, John Wiley \& Sons, 1972.

[2] M. J. Donachie, S. J. Donachie, Superalloys - A Technical Guide (2 $2^{\text {nd }}$ Edition), ASM International, Materials Park, 2002.

[3] A.M. Beltran; in C.T. Sims, N.S. Stoloff, W.C. Hagel, Superalloy II - High temperature materials for aerospace and industrial power, John Wiley, New York, 1987, pp. 135-163.

[4] S. Michon, P. Berthod, L. Aranda, C. Rapin, R. Podor, P. Steinmetz, Calphad 27 (2003) 289-294.

[5] P. Berthod, S. Michon, L. Aranda, S. Mathieu, J.C. Gachon, Calphad 27 (2003) 353-359.

[6] P. Berthod, Journal of Alloys and Compounds 481 (2009) 746-754.

[7] P. Berthod, Materials Science: An Indian Journal 9(11) 420-427.

[8] W. S. Lee, M. G. Kim, Han'guk Pusik Hakhoechi 24(2) (1995) 124-133.

[9] N. Maragoudakis, D. Tsipas, V. Eggonopoulos-Papadopoulos, Romanian Journal of Physics 49(3-4) 245-250.

[10] K. Ishii, M. Kohno, S. Ishikawa, S. Satoh, Materials Transactions JIM, 39(10) 1040-1045.

[11] T. Amano, T. Ozawa, K. Kudo, N. Matsumoto, N. Sakai, H. Isobe, Journal of Advanced Science 13(1-2) (2001) 64-65.

[12] X. Chunmei, J. Guo, F. Yang, Jinshu Xuebao 37(8) (2001) 857-860.

[13] Z. Wang, L. Zhou, J. Guo, Y. Liang, Z. Hu Cailiao Yanjiu Xuebao, 24(6) 585-591.

[14] H. Gui, L. Sun, H. Li, S. Gong, Thin Solid Films 516(16) (2008) 5732-5735.

[15] P. Song, J. Lu, D. Zhang, J. Lu, D. Li Jinshu Xuebao 47(6) (2011) 655-662. 
[16] P. Berthod, C. Heil, L. Aranda, Journal of Alloys and Compounds 504 (2010) 243-250.

[17] L. Corona, P. Berthod, Materials Science: An Indian Journal, in press.

[18] P. Berthod, P. Lemoine, J. Ravaux, Journal of Alloys and Compounds 467 (2009) 227-234.

[19] G. V. Samsonov, High-Temperature Materials - Properties Index, Plenum Press, New York, 1964.

[20] G. Michel, P. Berthod, M. Vilasi, S. Mathieu, P. Steinmetz, Surface \& Coatings Technology 205 (2011) 3708-3715. 


\section{TABLES}

Table 1

General chemical compositions of the studied alloys (as-cast) (SEM/EDS, $\pm 1 \mathrm{wt} . \%$ for all elements except $\mathrm{C}^{*}$ )

\begin{tabular}{|c|c|c|c|c|}
\hline $\begin{array}{c}\text { Alloy (as-cast) } \\
(\text { all fields } \times 1000)\end{array}$ & \multicolumn{2}{|l|}{ Chromium } & \multicolumn{2}{l|}{ Hafnium } \\
\cline { 2 - 5 } Co-25Cr & 25.92 & 0.23 & $/$ & $/$ \\
\hline Co-25Cr-0.25C & 25.43 & 0.14 & $/$ & $/$ \\
\hline Co-25Cr-0.50C & 25.56 & 0.16 & $/$ & $/$ \\
\hline Co-25Cr-1.00C & 27.16 & 0.13 & $/$ & $/$ \\
\hline Co-25Cr-0.25C-3.72Hf & 25.38 & 0.18 & 3.97 & 0.22 \\
\hline Co-25Cr-0.50C-3.72Hf & 25.84 & 0.21 & 3.46 & 0.13 \\
\hline Co-25Cr-0.50C-7.44Hf & 25.35 & 0.67 & 10.19 & 1.99 \\
\hline
\end{tabular}

Table 2

Chemical compositions of the matrixes of the as-cast alloys $\left(\mathrm{SEM} / \mathrm{EDS}, \pm 1 \mathrm{wt} . \%\right.$ for all elements except $\mathrm{C}^{*}$ )

\begin{tabular}{|c|c|c|c|c|}
\hline \multirow{2}{*}{ Matrix of ... (as-cast) } & \multicolumn{2}{|c|}{ Chromium } & \multicolumn{2}{l|}{ Hafnium } \\
\cline { 2 - 5 } & average & std dev. & average & std dev. \\
\hline Co-25Cr & 26.59 & 1.77 & $/$ & $/$ \\
\hline Co-25Cr-0.25C & 23.95 & 0.56 & $/$ & $/$ \\
\hline Co-25Cr-0.50C & 24.18 & 1.00 & $/$ & $/$ \\
\hline Co-25Cr-1.00C & 22.44 & 0.39 & $/$ & $/$ \\
\hline Co-25Cr-0.25C-3.72Hf & 25.14 & 0.25 & $\begin{array}{c}0.11 \\
(\min : \\
0.08)\end{array}$ & 0.04 \\
\hline Co-25Cr-0.50C-3.72Hf & 24.68 & 0.27 & $\begin{array}{c}0.04 \\
(\min : \\
0.00)\end{array}$ & 0.03 \\
\hline Co-25Cr-0.50C-7.44Hf & 26.46 & 0.26 & $\begin{array}{c}0.08 \\
(\mathrm{~min}: \\
0.03)\end{array}$ & 0.06 \\
\hline
\end{tabular}


Table 3

General chemical compositions of the alloys after $50 \mathrm{~h}$ at $1200^{\circ} \mathrm{C}$

(SEM/EDS, $\pm 1 \mathrm{wt} . \%$ for all elements except $\mathrm{C}^{*}$ )

\begin{tabular}{|c|c|c|c|c|}
\hline \multirow{2}{*}{$\begin{array}{c}\left.\text { Alloy (heated } 50 \mathrm{~h} 1200^{\circ} \mathrm{C}\right) \\
(\text { all fields } \times 1000)\end{array}$} & \multicolumn{2}{|c|}{ Chromium } & \multicolumn{2}{|c|}{ Hafnium } \\
\hline & average & std dev. & average & std dev. \\
\hline Co- $25 \mathrm{Cr}-0.25 \mathrm{C}$ & 25.04 & 0.19 & / & l \\
\hline Co- $25 \mathrm{Cr}-0.50 \mathrm{C}$ & 25.51 & 0.15 & / & l \\
\hline Co-25Cr-0.25C-3.72Hf & 25.58 & 0.24 & 3.65 & 1.12 \\
\hline $\mathrm{Co}-25 \mathrm{Cr}-0.50 \mathrm{C}-3.72 \mathrm{Hf}$ & 25.39 & 0.28 & 4.01 & 0.98 \\
\hline $\mathrm{Co}-25 \mathrm{Cr}-0.50 \mathrm{C}-7.44 \mathrm{Hf}$ & 25.26 & 0.04 & 10.29 & 0.41 \\
\hline
\end{tabular}

Table 4

Chemical compositions of the matrixes of the alloys after $50 \mathrm{~h}$ at $1200^{\circ} \mathrm{C}$ (SEM/EDS, $\pm 1 \mathrm{wt} . \%$ for all elements except $\mathrm{C}^{*}$ )

\begin{tabular}{|c|c|c|c|c|}
\hline $\begin{array}{c}\text { Matrix of ... (heated 50h } \\
\left.1200^{\circ} \mathrm{C}\right)\end{array}$ & \multicolumn{2}{|l|}{ Chromium } & \multicolumn{2}{l|}{ Hafnium } \\
\cline { 2 - 5 } & $\begin{array}{c}\text { average } \\
\text { Co-25Cr-0.25C }\end{array}$ & std dev. & average & std dev. \\
\hline Co-25Cr-0.50C & 25.50 & 0.26 & $/$ & $/$ \\
\hline Co-25Cr-0.25C-3.72Hf & 26.13 & 0.29 & $\begin{array}{c}0.00 \\
(\mathrm{~min}: \\
0.00)\end{array}$ & 0.00 \\
\hline Co-25Cr-0.50C-3.72Hf & 26.23 & 0.32 & $\begin{array}{c}0.00 \\
(\mathrm{~min}: \\
0.00)\end{array}$ & 0.00 \\
\hline Co-25Cr-0.50C-7.44Hf & 27.72 & 0.14 & $\begin{array}{c}0.03 \\
(\mathrm{~min}: \\
0.00)\end{array}$ & 0.06 \\
\hline
\end{tabular}




\section{FIGURES}
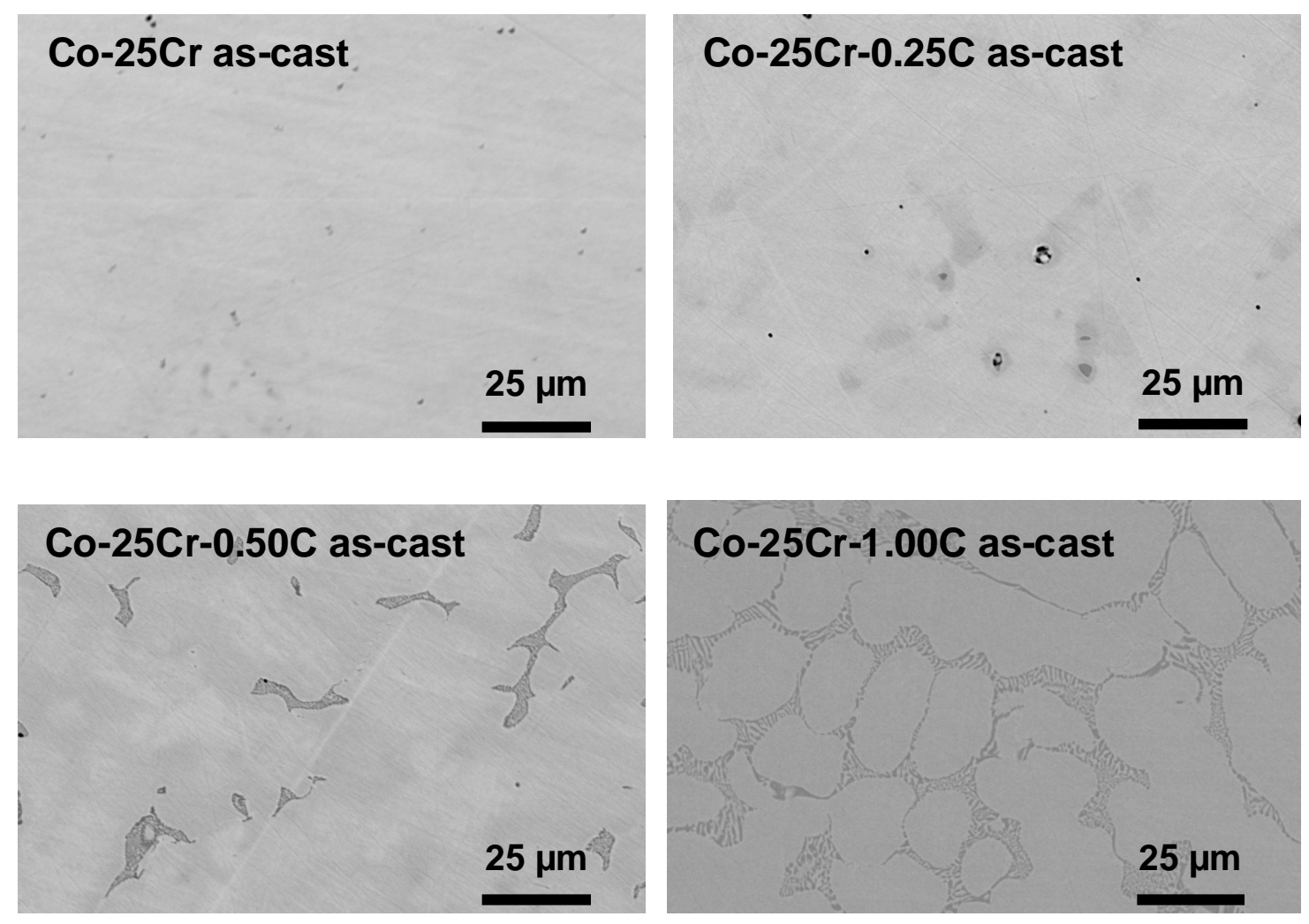

Fig. 1. As-cast microstructures of the four Hf-free alloys elaborated for the comparative study (SEM/BSE micrographs) 


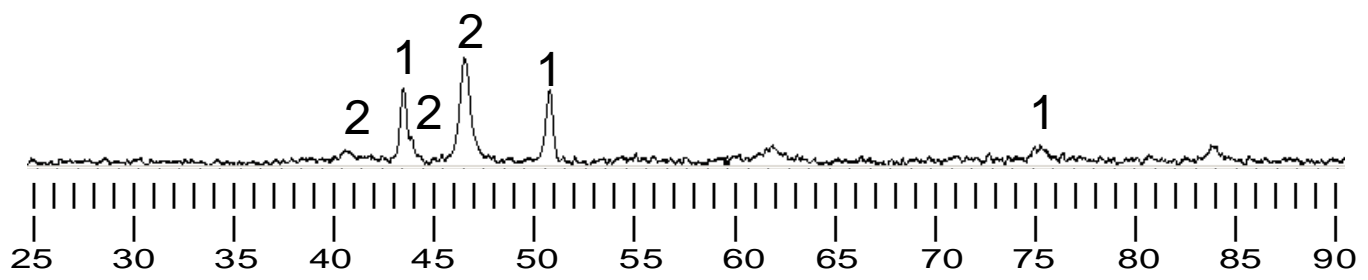

Co-25Cr-0.25C as-cast

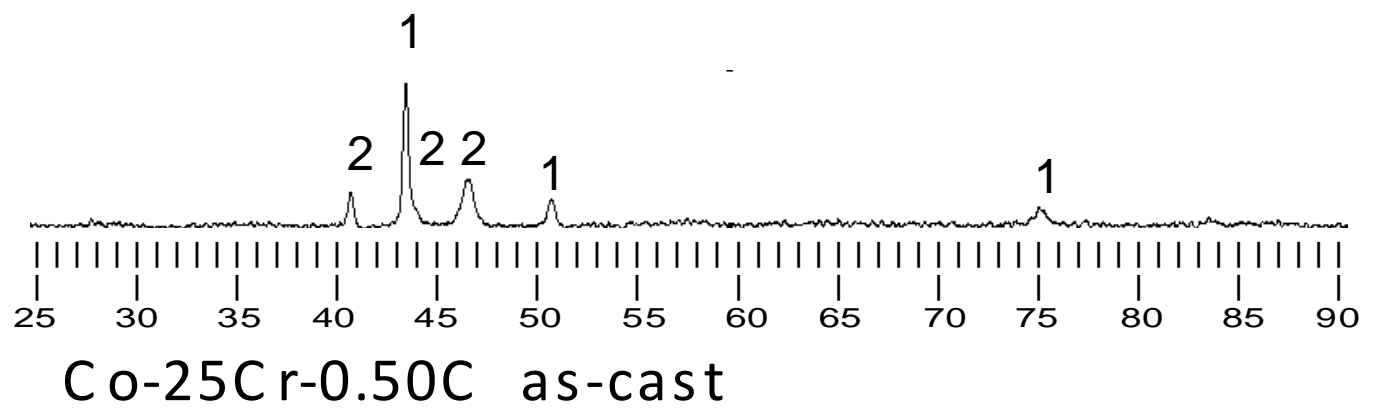

(1: Cofcc, 2: Co hcp)

Fig. 2. X-ray diffractograms obtained for two of the four as-cast Hf-free alloys 


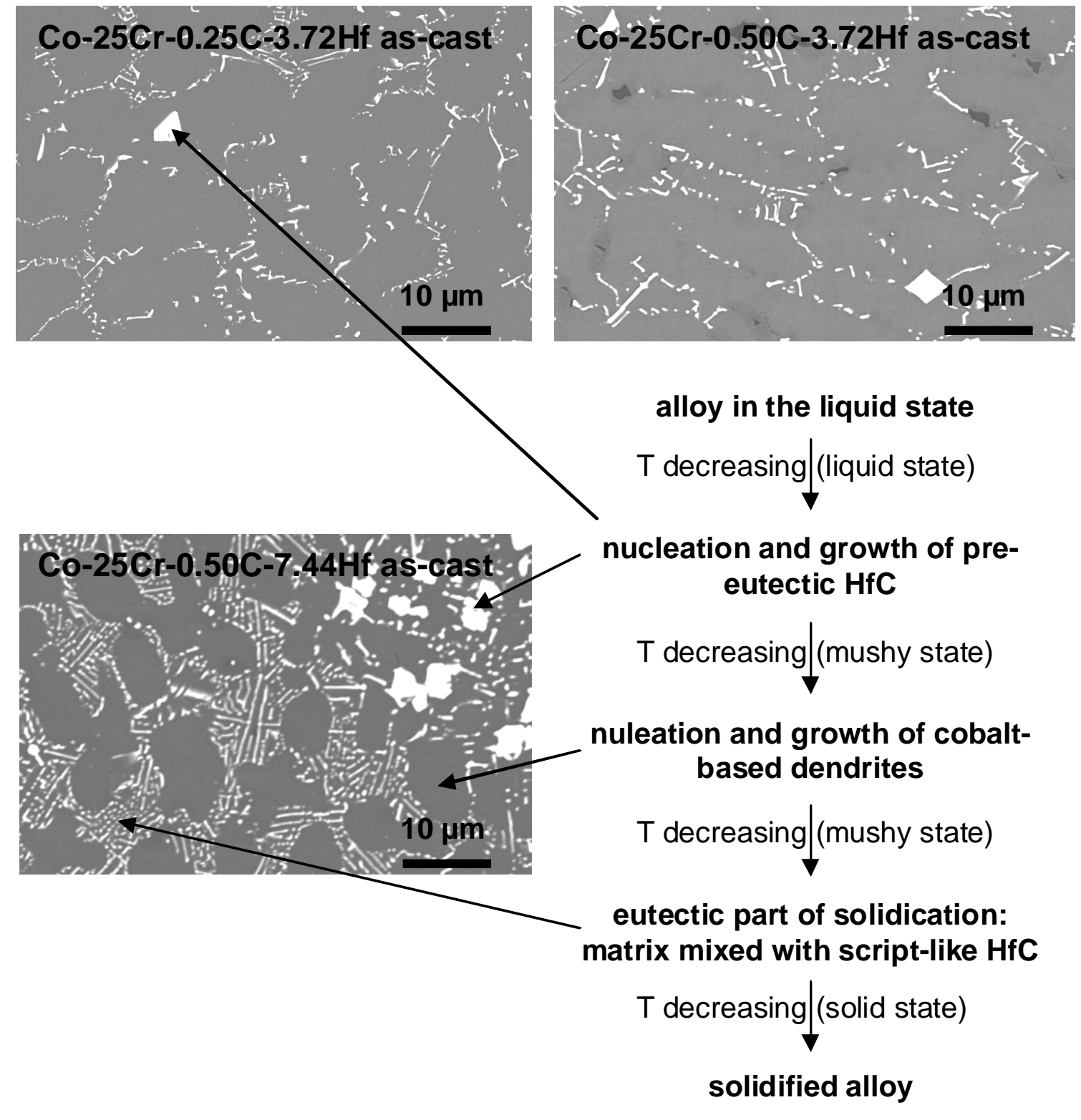

Fig. 3.

As-cast microstructures of the three Hf-rich alloys (SEM/BSE micrographs) and scheme explaining the successive solidification sequences (crystallization of pre-eutectic HfC and eutectic HfC) 

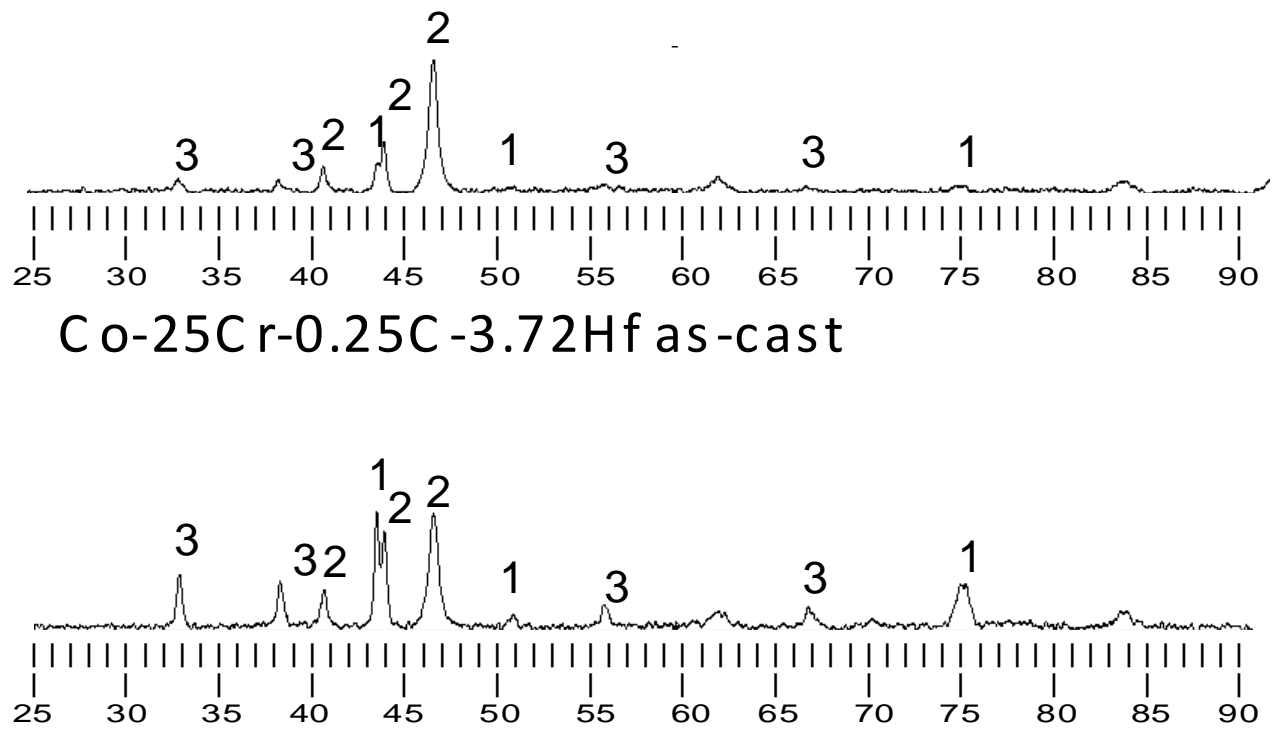

C o- $25 \mathrm{Cr}-0.50 \mathrm{C}-7.44 \mathrm{Hf}$ as-cast

\section{(1: Cofcc, 2: Co:hcp, 3: HfC carbides)}

Fig. 4. X-ray diffractograms obtained for two of the three as-cast Hf-rich alloys 

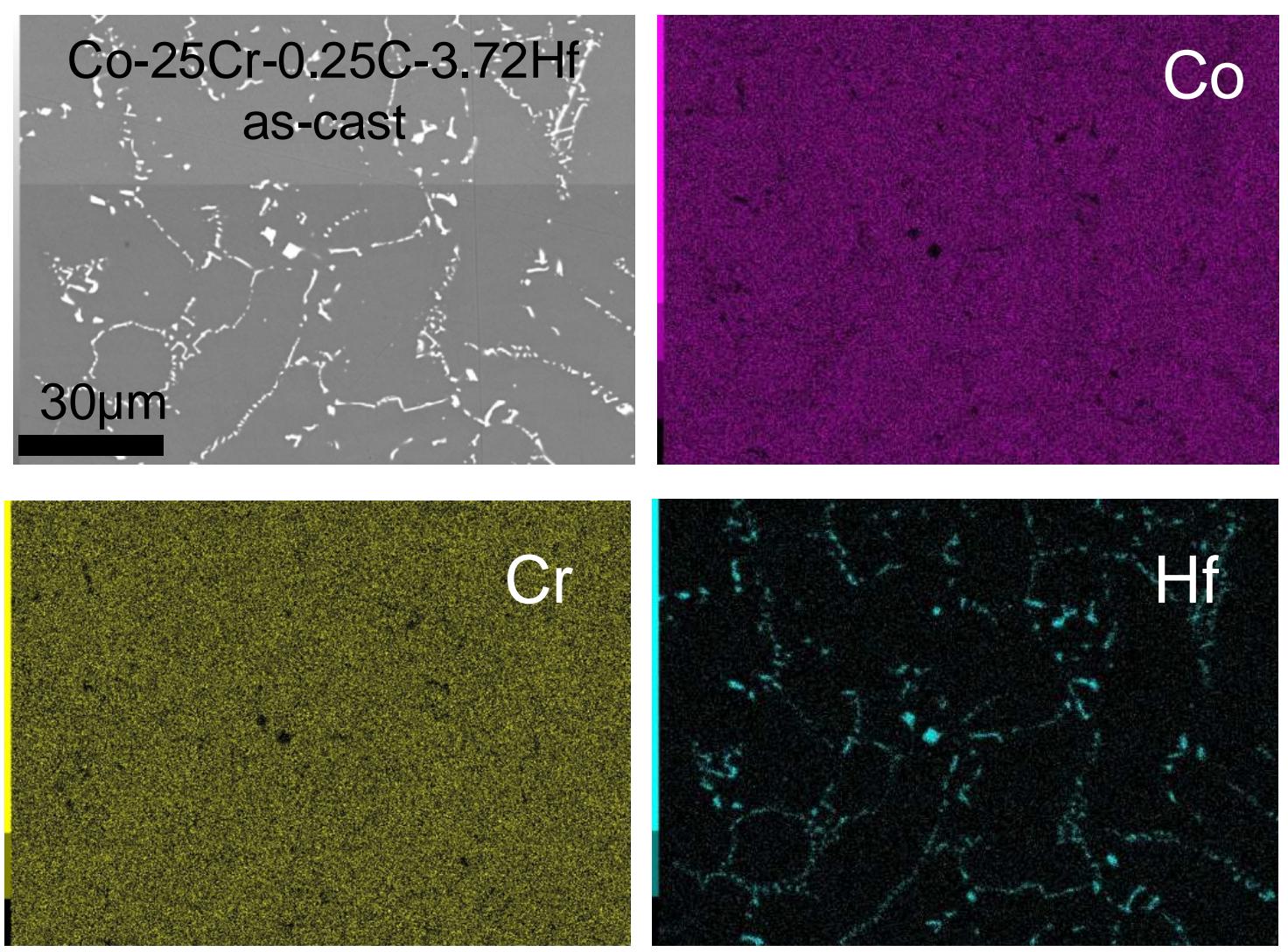

Fig. 5. X-ray maps showing the repartition of the main elements (Co, $\mathrm{Cr}$ and $\mathrm{Hf})$ in the microstructure of the Co-25Cr-0.25C-3.72Hf alloy 


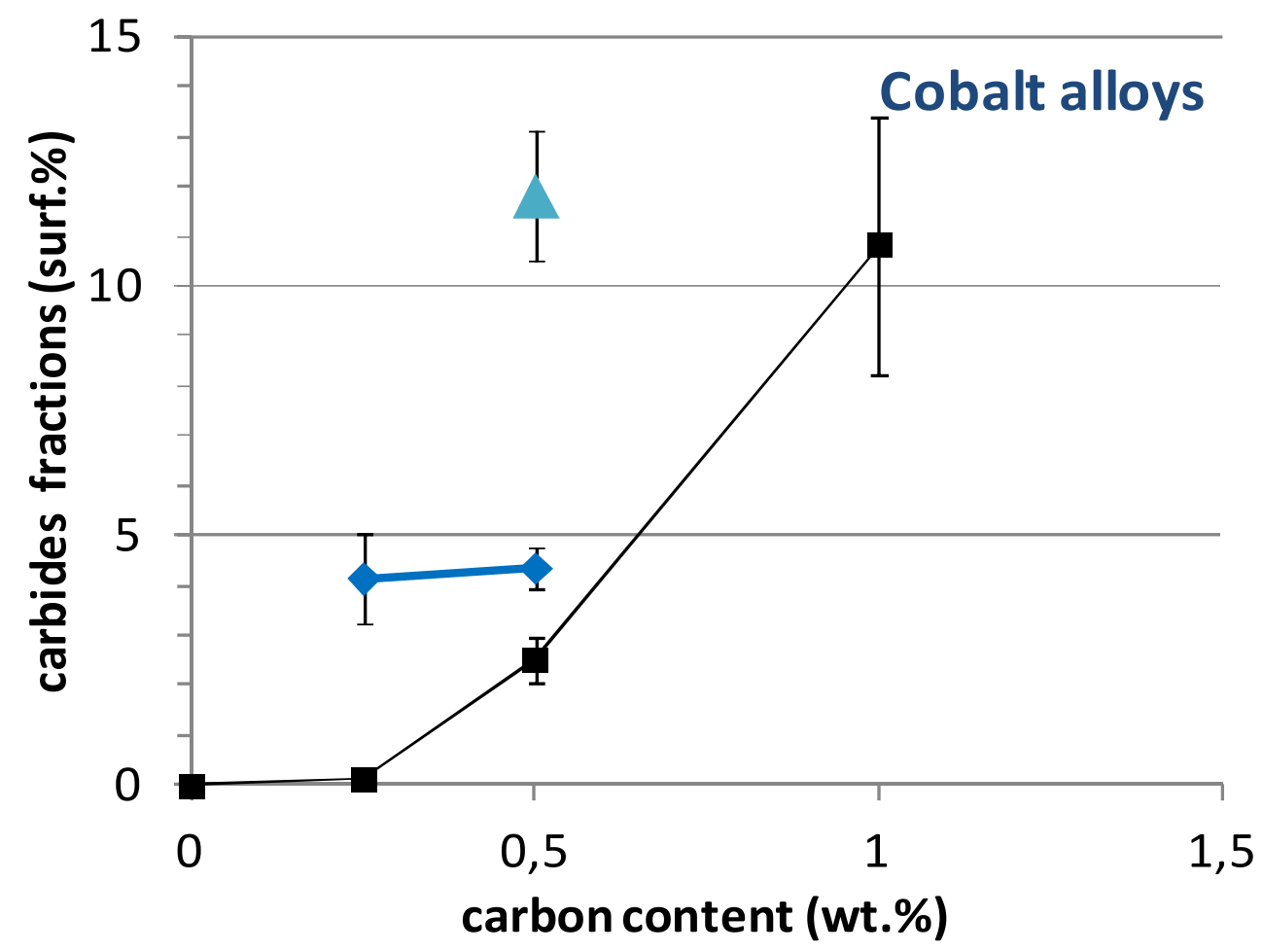

$\Delta \quad$ Co-25Cr-0.50C-7.44Hf (only HfC)

Co-25Cr-0.25C-3.72Hf (only HfC)

$\neg$ and Co-25Cr-0.50C-3.72Hf (mainly HfC, with $0.63 \pm 0.13$ surf.\% of chromium carbides)

$\rightarrow$ Binary and ternary chromium carbides (chromium carbides)

Fig. 6. Surface fraction of the carbides in all the as-cast alloys measured by image analysis and plotted versus the carbon content in the alloy (average values and standard deviations from three $\{\times 1000\}$ SEM/BSE micrographs) 

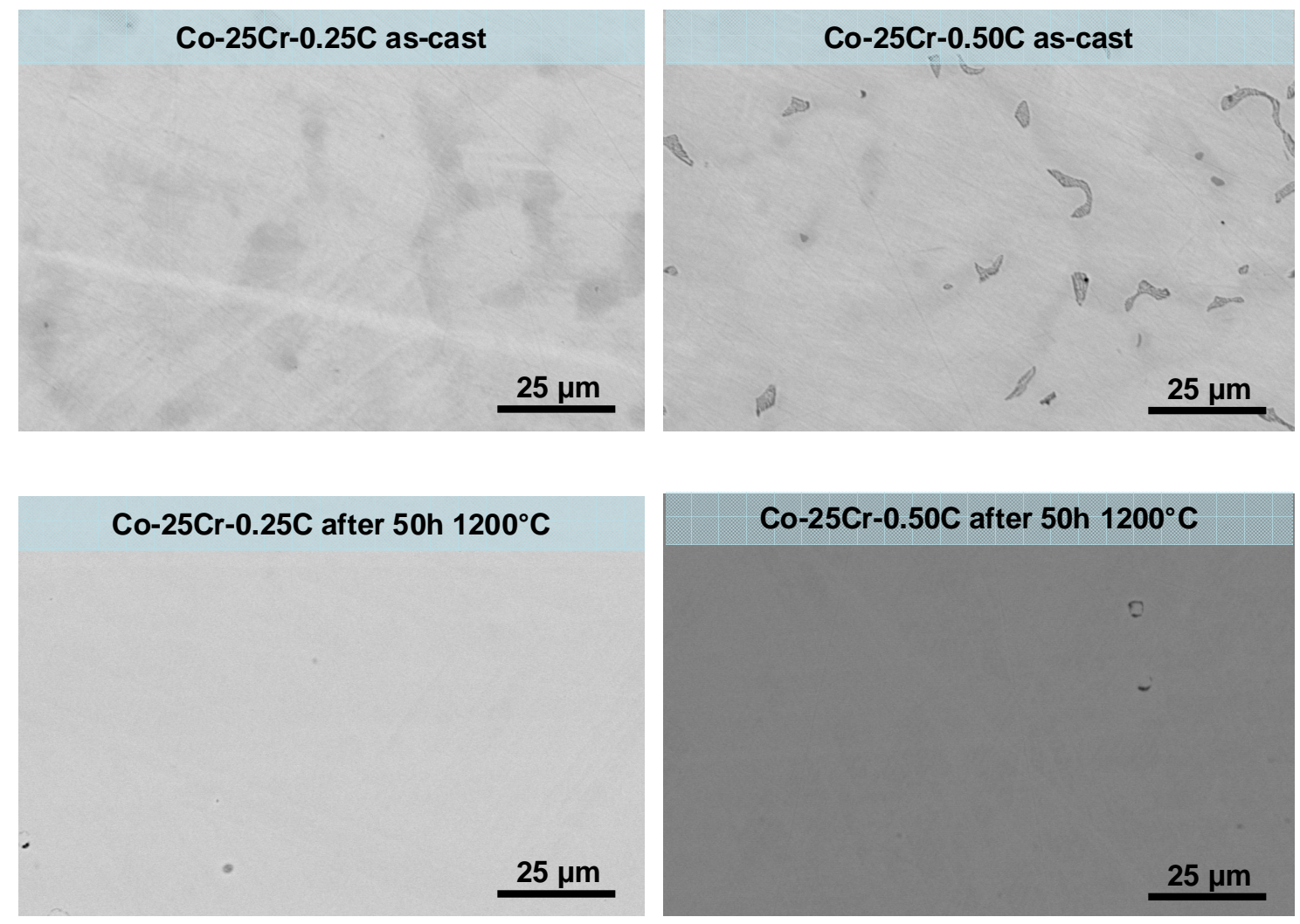

Fig. 7. Microstructures of the two ternary alloys after $50 \mathrm{~h}$ at $1200^{\circ} \mathrm{C}$; comparison with the as-cast microstructures (SEM/BSE) 

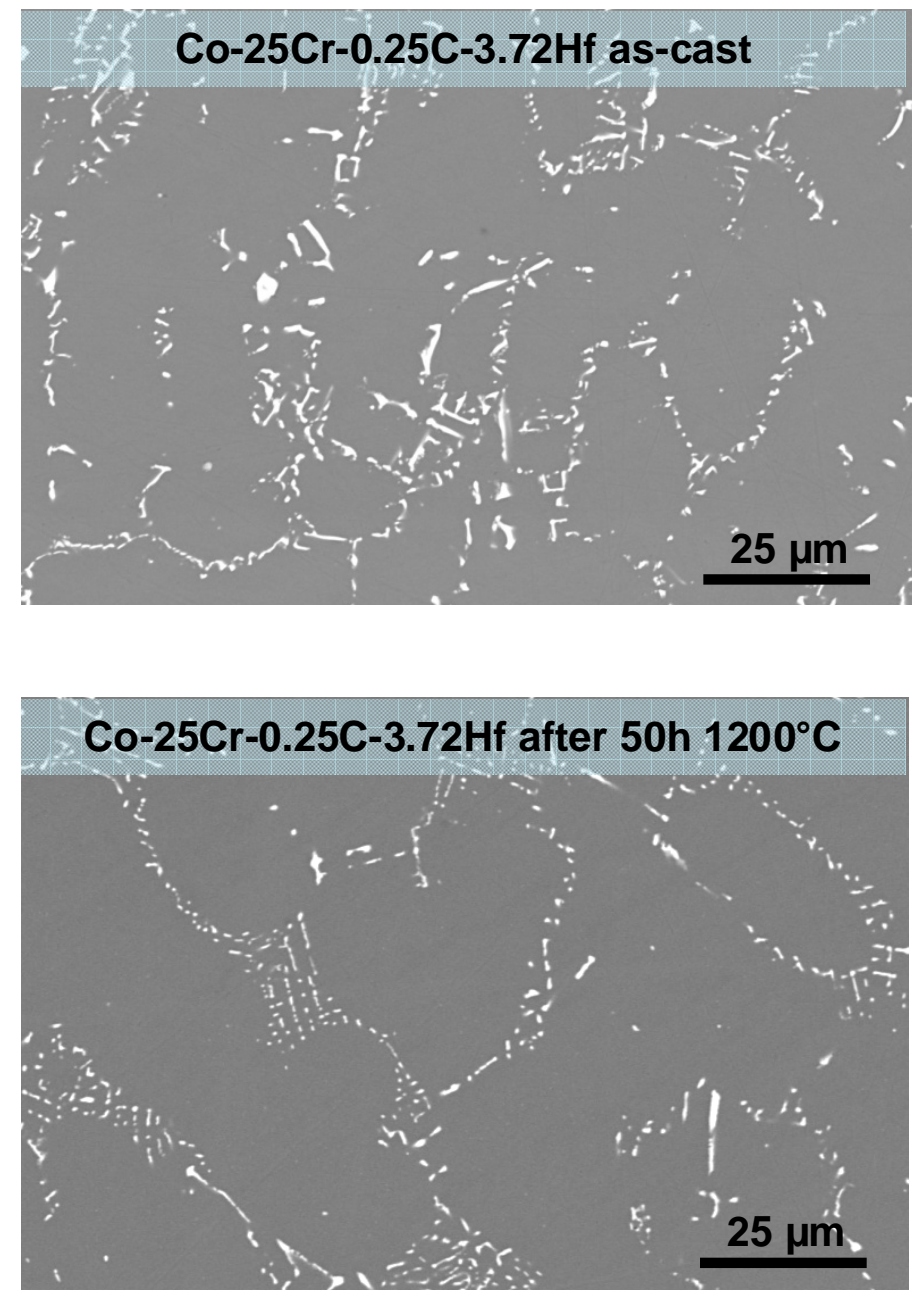

Fig. 8. Microstructures of the $\{0.25 \mathrm{wt} . \% \mathrm{C} ; 3.72 \mathrm{wt} . \% \mathrm{Hf}\}$-containing alloy after $50 \mathrm{~h}$ at $1200^{\circ} \mathrm{C}$; comparison with its as-cast microstructure (SEM/BSE) 

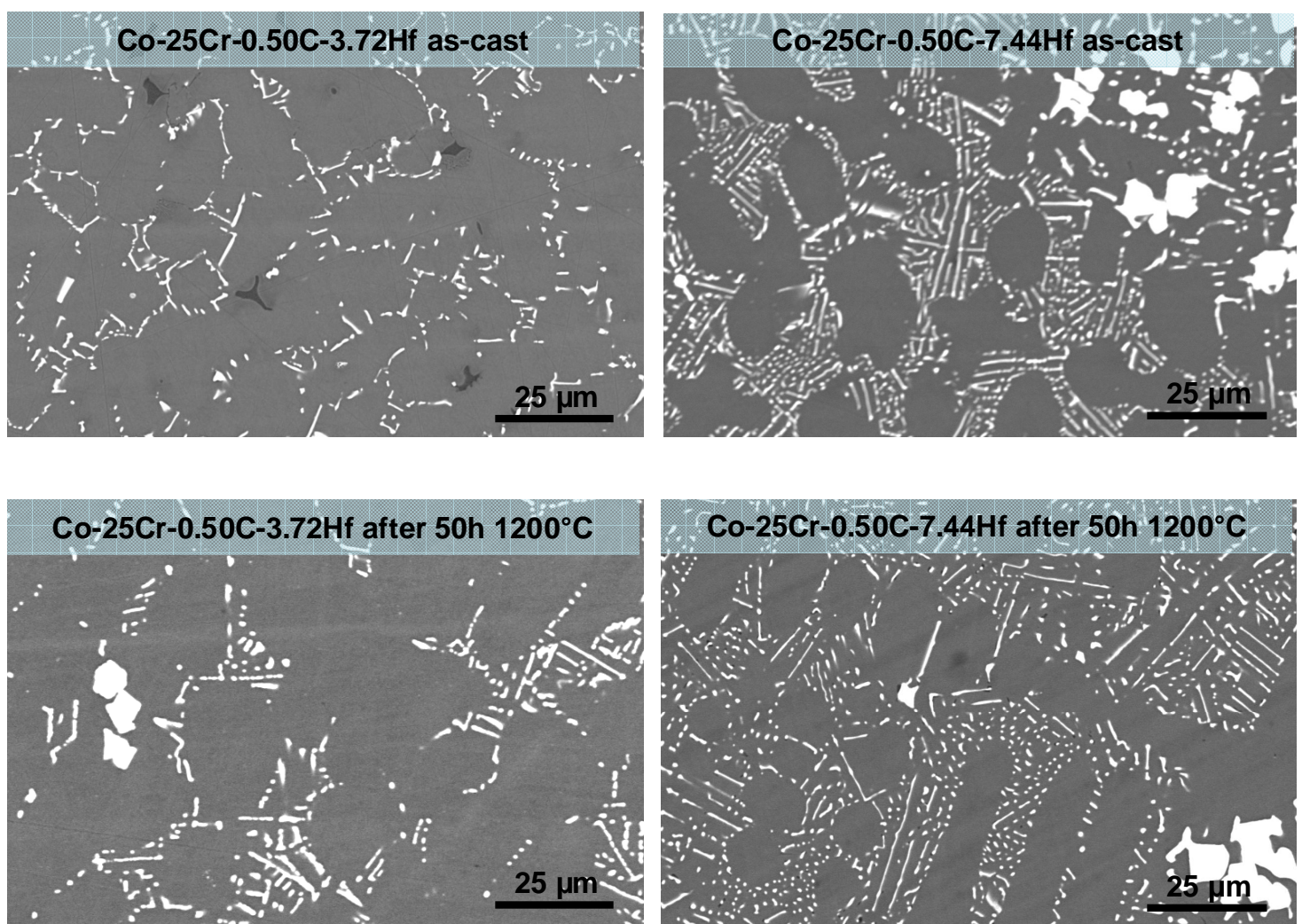

Fig. 9. Microstructures of the two $\{0.50 \mathrm{wt} . \% \mathrm{C}\}$-containing alloy after $50 \mathrm{~h}$ at $1200^{\circ} \mathrm{C}$; comparison with their as-cast microstructures (SEM/BSE) 


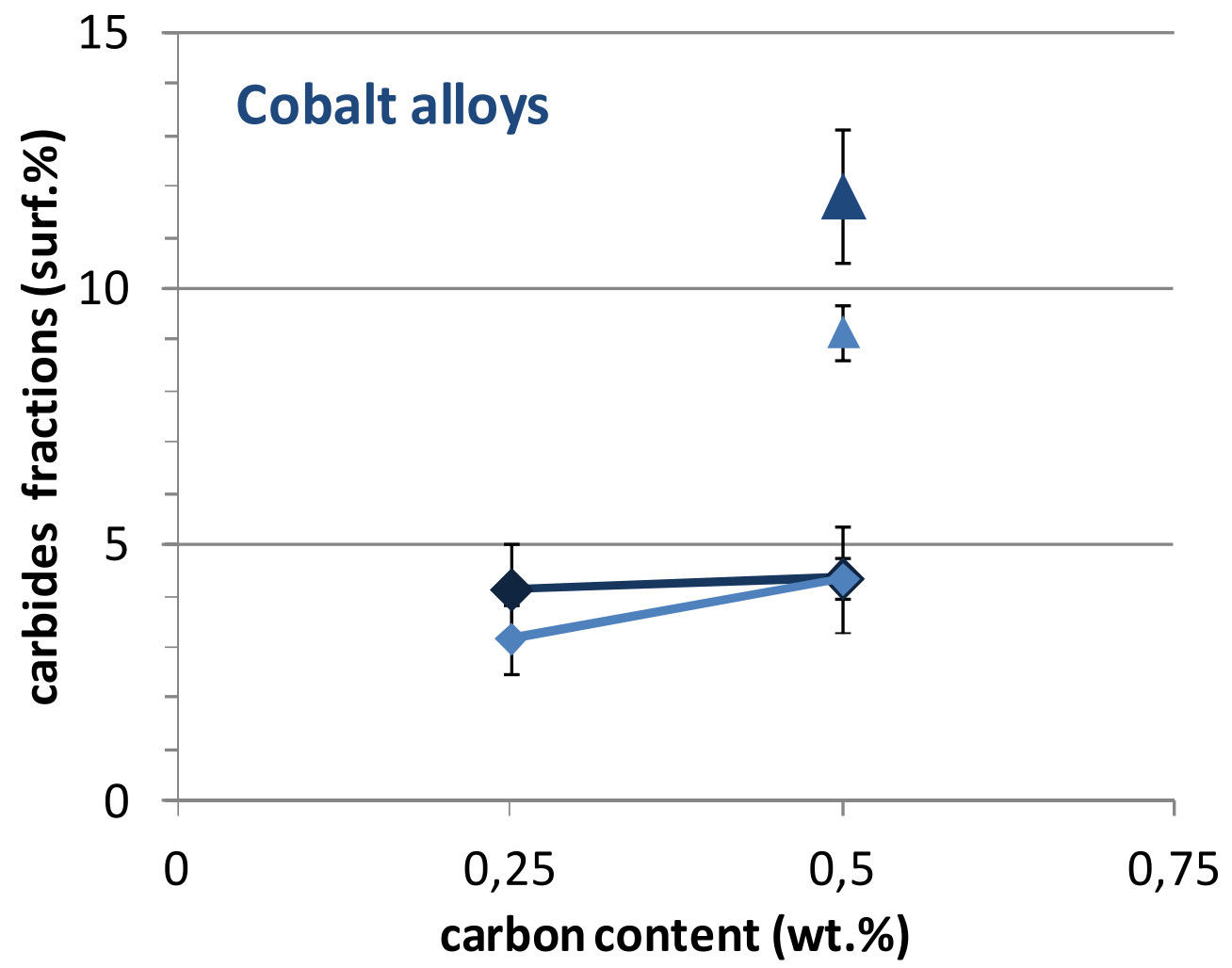

$\Delta$ Co-25Cr-0.50C-7.44Hf as-cast (only HfC)

Co-25Cr-0.50C-7.44Hf after $50 \mathrm{~h}$ at $1200^{\circ} \mathrm{C}$ (only HfC)

Co-25Cr-0.25C-3.72Hf (only HfC) and Co-25Cr-0.50C-3.72Hf (mainly $\mathrm{HfC}$, with $0.63 \pm 0.13$ surf.\% of chromium carbides)

Co-25Cr-0.25C-3.72Hf (only HfC) and Co-25Cr-0.50C-3.72Hf (only $\mathrm{HfC}$ )

Fig. 10. Surface fraction of the carbides in the Hf-rich alloys after exposure to $1200^{\circ} \mathrm{C}$ for 50 hours

(average values and standard deviations from three $\{\times 1000\}$ SEM/BSE micrographs) 


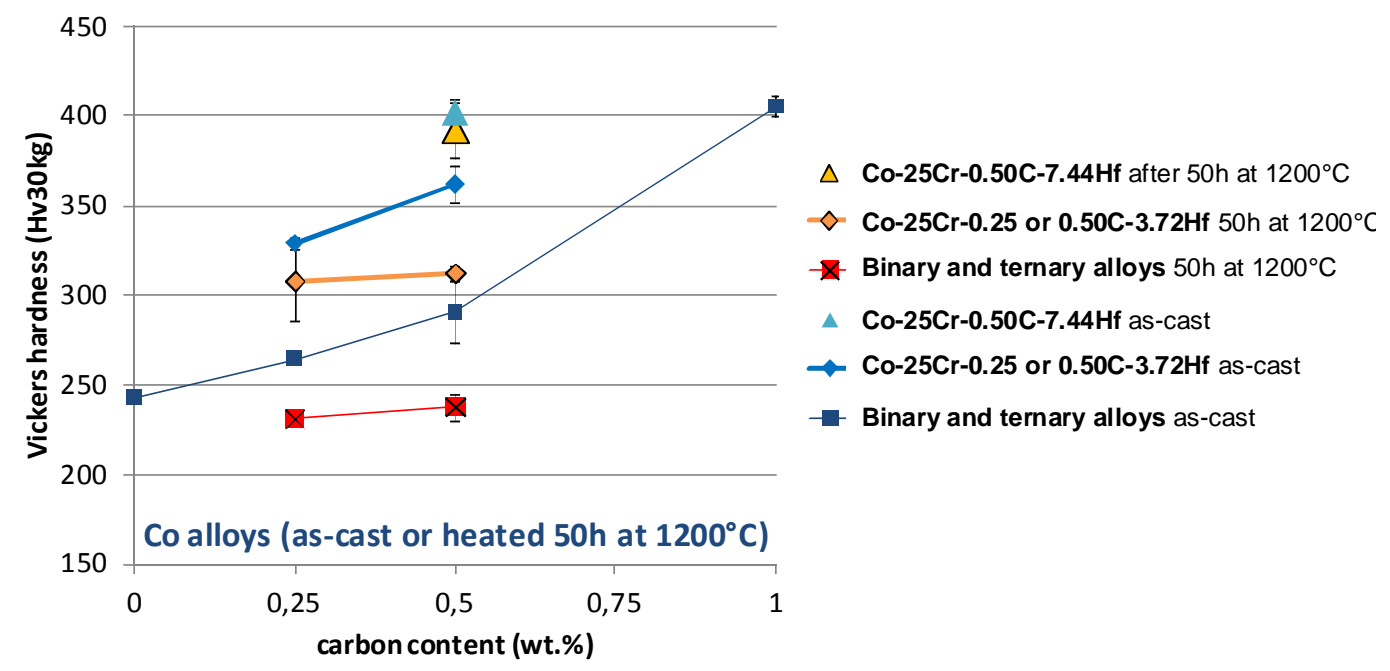

Fig. 11. Hardness of the seven alloys in their as-cast condition and of the five aged alloys after their exposure to $1200^{\circ} \mathrm{C}$ for 50 hours

(average and standard values of the Vickers hardness measured with a 30kg-load) 


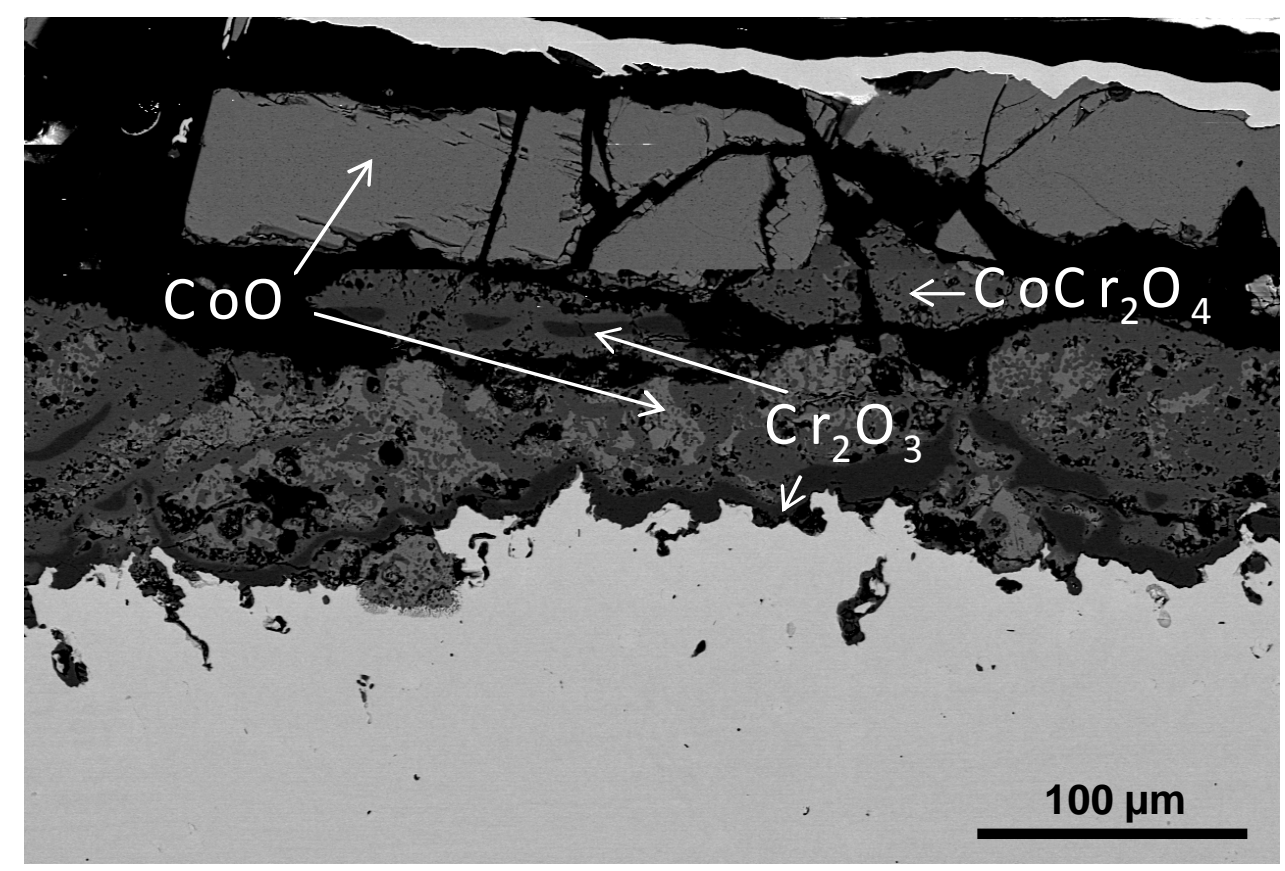

C $0-25 \mathrm{Cr}-0.25 \mathrm{C}$ exposed $50 \mathrm{~h}$ at $1200^{\circ} \mathrm{C}$

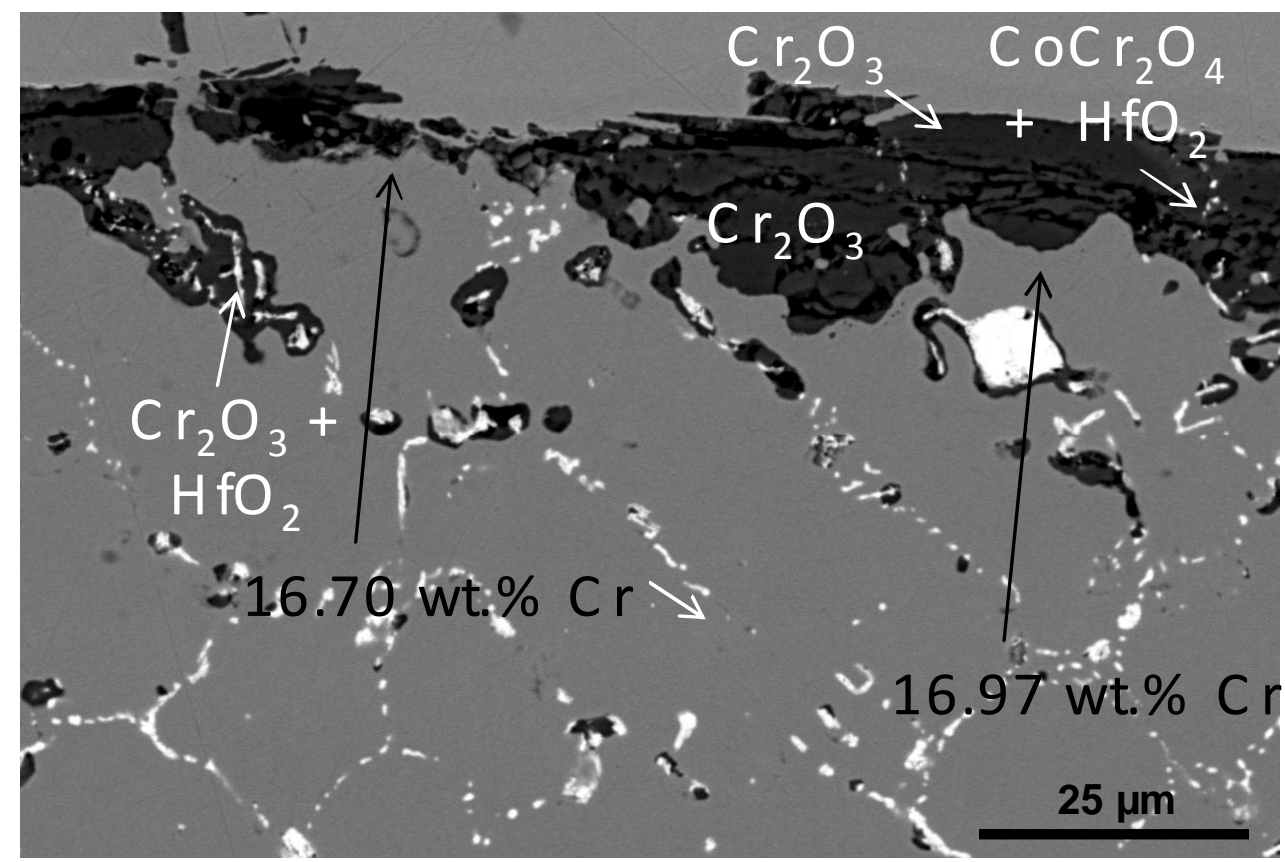

C $0-25 \mathrm{Cr}-0.25 \mathrm{C}-3.72 \mathrm{Hf}$ exposed $50 \mathrm{~h}$ at $1200^{\circ} \mathrm{C}$

Fig. 12. Surface states of the two $0.25 \mathrm{wt}$. $\%$-containing alloys after exposure at $1200^{\circ} \mathrm{C}$ for 50 hours (SEM/BSE micrographs) 


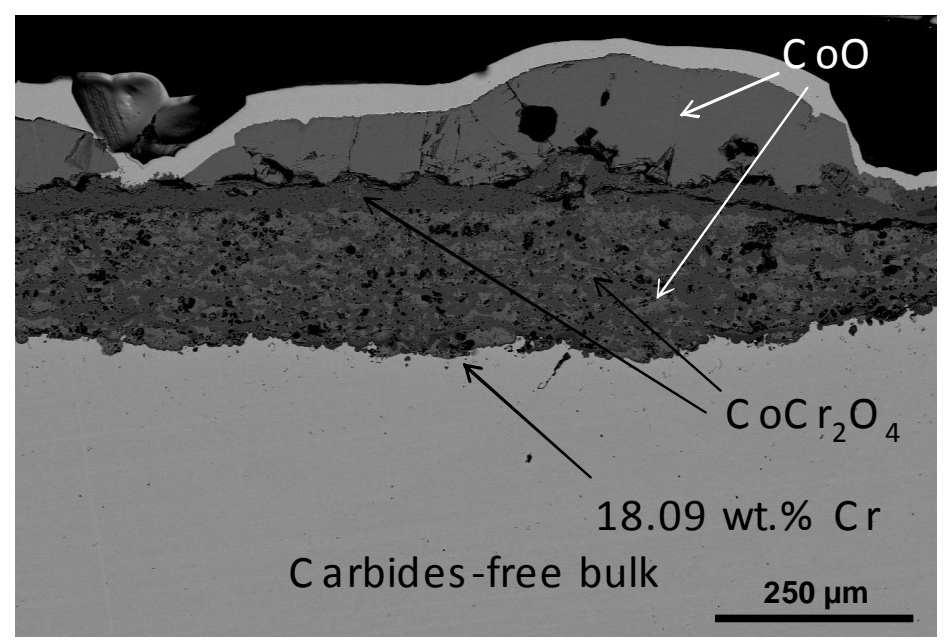

Co-25C r- $0.5 \mathrm{C}$ exposed $50 \mathrm{~h}$ at $1200^{\circ} \mathrm{C}$

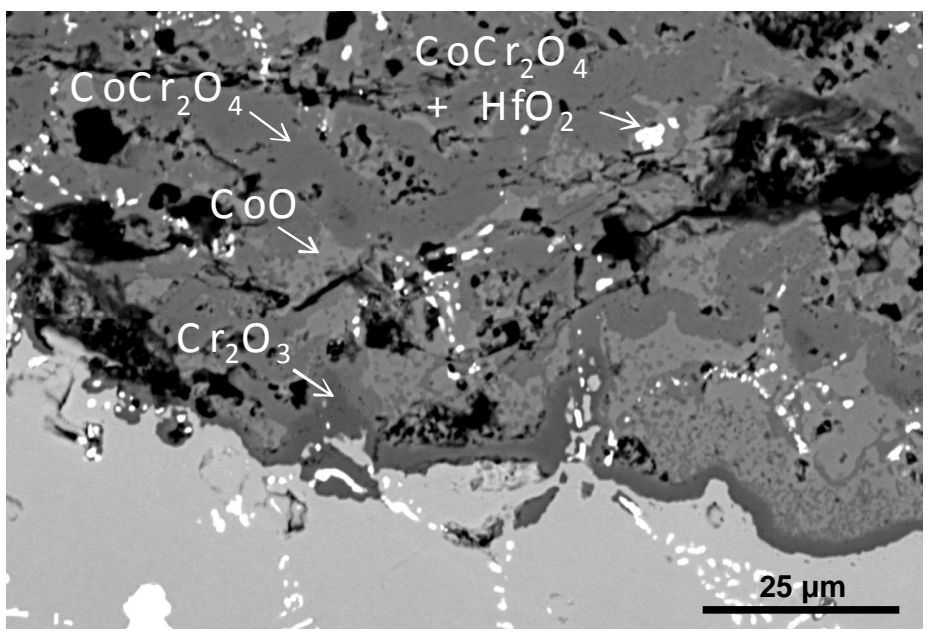

C $0-25 \mathrm{Cr}-0.50 \mathrm{C}-3.72 \mathrm{Hf}$ exposed $50 \mathrm{~h}$ at $1200^{\circ} \mathrm{C}$

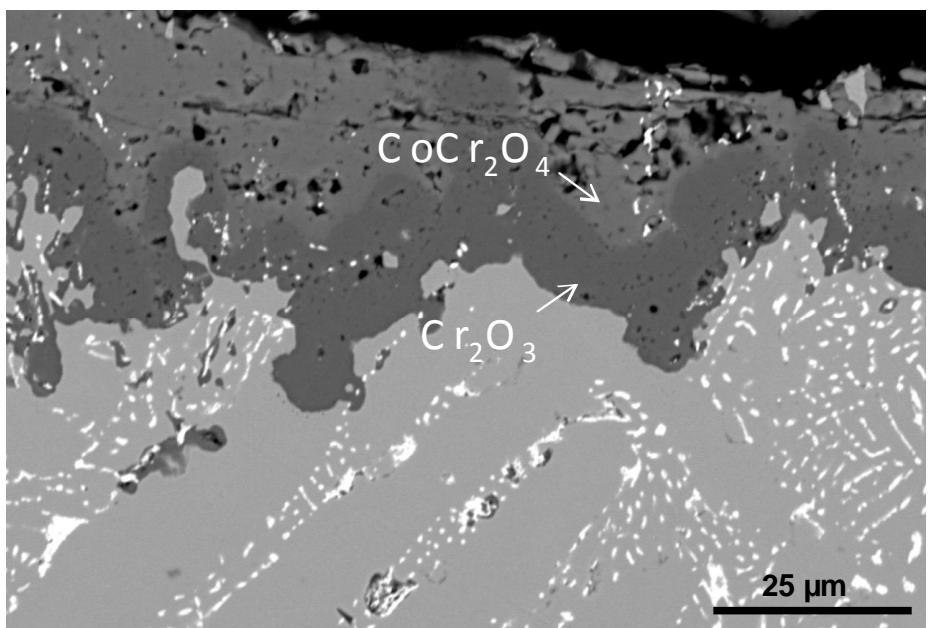

$\mathrm{Co}-25 \mathrm{Cr}-0.50 \mathrm{C}-7.44 \mathrm{Hf}$ exposed $50 \mathrm{~h}$ at $1200^{\circ} \mathrm{C}$

Fig. 13. Surface states of the two $0.50 \mathrm{wt} \%$-containing alloys after exposure at $1200^{\circ} \mathrm{C}$ for 50 hours (SEM/BSE micrographs) 